\title{
Varicocele: A Review
}

\author{
Brian F. Baigorri, MD ${ }^{1}$ Robert G. Dixon, MD ${ }^{1}$ \\ ${ }^{1}$ Department of Radiology, University of North Carolina, Chapel Hill, \\ Address for correspondence Robert G. Dixon, MD, Department of \\ North Carolina \\ Radiology, University of North Carolina, 2016 Old Clinic Building, CB \\ 7510, Chapel Hill, NC 27517 (e-mail: Bob_Dixon@med.unc.edu).
}

Semin Intervent Radiol 2016;33:170-176

\begin{abstract}
Keywords

- varicocele

- infertility

- embolization

- orchalgia

- interventional radiology

Varicoceles are relatively common clinical problem that are associated with pain, testicular atrophy, and reduced fertility rates. After a brief historical perspective is presented, this article reviews the anatomy, indications, treatment options, and potential complications related to varicoceles.
\end{abstract}

Objectives: Upon completion of this article, the reader will be able to discuss the anatomy, indications, treatment options, and complications related to varicoceles.

Accreditation: This activity has been planned and implemented in accordance with the Essential Areas and Policies of the Accreditation Council for Continuing Medical Education (ACCME) through the joint providership of Tufts University School of Medicine (TUSM) and Thieme Medical Publishers, New York. TUSM is accredited by the ACCME to provide continuing medical education for physicians.

Credit: Tufts University School of Medicine designates this journal-based CME activity for a maximum of 1 AMA PRA Category 1 Credit $^{\mathrm{TM}}$. Physicians should claim only the credit commensurate with the extent of their participation in the activity

\section{Historical Overview}

Celsus provided a detailed description of varicocele and its operative treatment in the first century AD. ${ }^{1,2}$ Since that time, a wide range of conservative therapies have been recommended including suspension, compression, cold scrotal showers, astringents, and moderation of sexual activity. ${ }^{1}$ Perhaps more interesting is the early evolution of surgical treatments, which involved a trans-scrotal approach and included cauterization, clamps, subcutaneous hoops, partial excision of the scrotum, ligation and resection of the dilated venous plexus, and even semicastration. ${ }^{1,3,4}$ This surgical approach remained in favor until 1898 when Narath first performed an inguinal approach to treat a varicocele. ${ }^{1}$ During several hernia operations in which varicoceles were identified, he resected the internal spermatic vein during a Bassini operation, resulting in a dramatic increase in the success rate for resolution of the varicocele. Since Narath published his results in $1900,{ }^{1}$ this surgical approach was further modified and developed by Ivanissevich and Gregorini ${ }^{5}$ and later by Bernardi, ${ }^{1}$ both of whom practiced in Buenos Aires. Paloma proposed and refined a high retroperitoneal surgical approach, which involved ligation of both the artery and vein above the level of the deep inguinal ring. ${ }^{6,7}$ Reports by Tulloch in the 1950s first shed light on a relationship between varicocele and infertility, underscoring the concept that a varicocele is not an innocuous condition. ${ }^{1,8}$ More recently, laparoscopic approaches have been developed ${ }^{3,9}$ and imaging has improved dramatically. Spermatic venography was first used in 1977 to identify incompetent spermatic veins, with percutaneous embolization being initially described in $1978 .{ }^{3}$

\section{Anatomy}

Varicoceles are dilated tortuous veins of the pampiniform plexus-the venous sinuses that drain the testicles. These sinuses primarily drain into the internal spermatic vein (gonadal vein). The right internal spermatic vein normally drains obliquely into the anterolateral inferior vena cava (IVC), just inferior to the right renal vein, whereas the left spermatic vein normally drains perpendicularly into the left renal vein.
Issue Theme Men's Health; Guest Editor, Charles Burke, MD
Copyright @ 2016 by Thieme Medical Publishers, Inc., 333 Seventh Avenue, New York, NY 10001, USA. Tel: +1(212) 584-4662.
DOI http://dx.doi.org/ $10.1055 / \mathrm{s}-0036-1586147$. ISSN 0739-9529. 
The perpendicular termination exposes the left spermatic vein to compromised flow in the setting of increased left renal venous pressures. This flow abnormality is augmented when there is compression of the left renal vein between the aorta and superior mesenteric vein (SMV; "nutcracker syndrome"). ${ }^{10,11}$ Additionally, the increased length of the left-sided vein when compared with the right contributes to the increased prevalence of left -sided varicoceles. ${ }^{12}$ This difference in incidence is such that an isolated right varicocele is rare, and some investigators advocate prompt evaluation for a retroperitoneal mass. ${ }^{13}$ Another factor that predisposes to formation of a left-sided varicocele is compression of the left spermatic vein by the left colon. ${ }^{14}$

Valvular absence or malfunction contributes to venous reflux, which is more common in the left internal spermatic vein. In a postmortem evaluation series, absence of valves in $40 \%$ of left spermatic veins and $23 \%$ of right spermatic veins was noted. ${ }^{12}$

In order of importance, other drainage pathways of the testicle in order of importance include the external pudendal vein that drains into the great saphenous vein; the vasal vein, which drains into the internal iliac vein; and the cremasteric vein (external spermatic vein), which drains into the inferior epigastric vein and the external iliac vein. Additional collateral pathways may exist to the retroperitoneal, peritoneal, ureteral, splenic, colonic, and adrenal veins, with possible communication between the bilateral internal spermatic veins at the $\mathrm{L} 3$ level. ${ }^{15,16}$

Variant venous anatomy is not uncommon. Dissection of 150 cadavers revealed variant testicular vein anatomy in $21 \%$ of specimens, including duplication of spermatic veins and IVC termination of the left renal vein. ${ }^{17}$ Though uncommon, the right spermatic vein may drain directly into the right renal vein or duplicated right renal vein rather than the IVC. ${ }^{17,18}$ Another possible variant is drainage of the left spermatic vein into a branch of the left renal vein. ${ }^{19}$

\section{Incidence}

Reported incidence of varicoceles in the general population ranges from 15 to $20 \%,{ }^{12,20,21}$ and 30 to $40 \%$ in infertile men. $^{12,22}$ This prevalence increases with age, approaching $42 \%$ in the elderly population. ${ }^{23,24}$ Due to the anatomic causes described earlier, left-sided varicoceles are 10 times more common than on the right and occur bilaterally in fewer than $10 \%$ of patients and isolated to the right in less than $1 \%{ }^{16,25}$

In addition, genetics may add to the likelihood of developing a varicocele. A review of 62 first-degree relatives of patients with varicoceles found that $56.5 \%$ had palpable varicoceles, whereas the incidence in a control group of 263 was $6.8 \%{ }^{26}$

\section{Indications}

Indications for the treatment of varicoceles include infertility, testicular atrophy in the pediatric/adolescent population, and orchalgia. When treating for infertility, American Urological Association/American Society for Reproductive Medicine criteria advocate that varicocele be palpable; the couple has infertility;
Table 1 Criteria for treating varicoceles for infertility

\begin{tabular}{|l|}
\hline Palpable varicocele \\
\hline The couple is infertile \\
\hline $\begin{array}{l}\text { Female member of the couple has normal fertility or a } \\
\text { potentially treatable cause of infertility }\end{array}$ \\
\hline $\begin{array}{l}\text { Male member has abnormal semen parameters or } \\
\text { abnormal sperm function }\end{array}$ \\
\hline
\end{tabular}

the female has normal fertility or a potentially treatable cause of infertility; and the male has abnormal semen parameters or abnormal results of sperm function tests ( - Table $\mathbf{1}$ ). Additional indications include young men with a palpable varicocele, regardless of semen parameters, and adult men with varicoceles and altered semen parameters, regardless of whether they are currently attempting to conceive. ${ }^{22}$

The treatment of subclinical varicoceles, those that cannot be diagnosed solely on clinical exam and instead rely on additional diagnostic exams, ${ }^{27}$ is a controversial topic. Although many authors believe that there is little to no benefit in treating subclinical varicoceles for pain or fertility, ${ }^{28-32}$ several studies have found improvement in fertility following treatment. ${ }^{33-36}$

\section{Testicular Dysfunction}

Approximately $40 \%$ of men being evaluated for infertility have a varicocele. ${ }^{22}$ The etiology of this infertility is complex and thought to be related to decreased sperm quality and quantity from increased temperature, ${ }^{37-39}$ reflux of the adrenal vein into the spermatic vein inducing a catecholamine effect, ${ }^{40,41}$ hypoxia from venous stasis, and elevated spermatozoal oxygen species. $^{42,43}$

Regardless of fertility status, varicoceles may result in testicular atrophy. ${ }^{44}$ This loss in testicular mass is accompanied by dysfunctional testicular tissue, as evidenced by studies that have biopsied testicles with varicoceles. ${ }^{45,46}$

Orchalgia is present in approximately 2 to $10 \%$ of men with varicoceles, and is described as dull, throbbing pain exacerbated by straining and prolonged standing. ${ }^{47}$ This pain classically extends from the scrotum to the ipsilateral inguinal region following the path of the spermatic cord. ${ }^{48}$ Varicoceles have been identified as the cause for chronic scrotal pain in 2 to $14 \%$ of men. ${ }^{49-51}$

\section{Evaluation}

Evaluation should be performed in a warm room with the patient both recumbent and upright. If not obviously palpable but suspected, a Valsalva maneuver in the standing position may help engorge the dilated veins. Oftentimes, the varicocele reduces during the supine position. ${ }^{12} \mathrm{~A}$ varicocele grading system based on physical exam was proposed by Dubin and Amelar (-Table 2). ${ }^{52}$

Although not routinely used in diagnosing varicoceles, ultrasound is a valuable asset in the detection of subclinical 
Table 2 Clinical grading of varicoceles

\begin{tabular}{|l|l|}
\hline \multicolumn{2}{|l|}{ Physical exam grading of varicoceles } \\
\hline Grade 1 & Palpable when the patient is standing and performing a Valsalva maneuver \\
\hline Grade 2 & Palpable when the patient is standing, without performing a Valsalva maneuver \\
\hline Grade 3 & Visible through the scrotal skin and palpable while the patient is standing \\
\hline
\end{tabular}

varicoceles, and in the evaluation for a postsurgical recurrence of persistence. ${ }^{12}$ On ultrasound, varicoceles will appear as tubular serpiginous hypoechoic structures along the superior lateral testis, generally measuring greater than $2 \mathrm{~mm}$ in diameter (-Fig. 1). Low-level echoes may be present, representing sluggish flow. ${ }^{53}$ Color Doppler can be used for diagnosing and grading varicoceles by documenting reversal of flow with or without performing a Valsalva maneuver (- Fig. 2a, b). Additionally, the use of ultrasound increases the sensitivity of detecting subclinical varicoceles. ${ }^{54}$ A proposed grading system for varicoceles according to color Doppler imaging stratifies patients into one of five grades ( - Table 3 ). ${ }^{55}$

\section{Surgical Treatment}

The Palomo technique, a retroperitoneal high ligation above the internal inguinal ring, was introduced in $1949 .{ }^{6}$ However, this technique had a high rate of recurrence because the superior point of ligation did not address collaterals. It also resulted in a lengthy patient recovery because it required dissection of the abdominal musculature. ${ }^{56}$ There have been modifications to this approach; however, treatment has shifted toward microsurgical inguinal or subinguinal varicocelectomy. ${ }^{57}$ Subinguinal varicocelectomy (with or without microsurgery) offers the advantage of avoiding the external oblique fascia and therefore minimizes postoperative pain. ${ }^{12}$

Laparoscopic varicocelectomy may also be performed. It is technically similar to the open retroperitoneal approach, as it involves high ligation of the spermatic vein without identification of the external spermatic vessels. Consequently, the incidence of postoperative hydrocele and recurrence is higher when compared with a microsurgical varicocelectomy. However, laparoscopic approaches do offer the advantage of treating bilateral varicoceles easily, as well as a quick recovery time. $^{12}$

\section{Endovenous Treatment}

Percutaneous varicocele embolization is routinely performed as an outpatient procedure using moderate sedation and with the patient in the supine position. The approach used and the catheters selected are operator dependent. A right common femoral vein approach is often used, especially when treating an isolated left varicocele. ${ }^{58-62}$ However, some operators may prefer a right internal jugular vein approach ${ }^{60}$; a transbrachial approach may offer similar advantages. ${ }^{63,64}$

Following venous access, a 7F sheath is placed. If using femoral access, a C2 or C1 angiographic diagnostic catheter (Cook Medical, Bloomington, IN) can be used to access the left renal vein and left internal spermatic vein $(-\mathbf{F i g} \cdot \mathbf{3 a}-\mathbf{c})$, whereas a reverse-curve catheter such as a Simmons-1 (Cook Medical, Bloomington, IN) is preferred for the right internal spermatic vein. A superior approach offers the advantage of using the same catheter for both the right and left internal spermatic vein, such as a JB1, H1H (Cook Medical, Bloomington, IN), or BentsonHanafee-Wilson 1 catheter (Terumo Medical Corporation, Somerset, NJ). Retrograde venography is performed once the catheter has engaged the internal spermatic vein. This should be repeated while the patient either performs the Valsalva maneuver or is placed in reverse Trendelenburg. This latter venogram

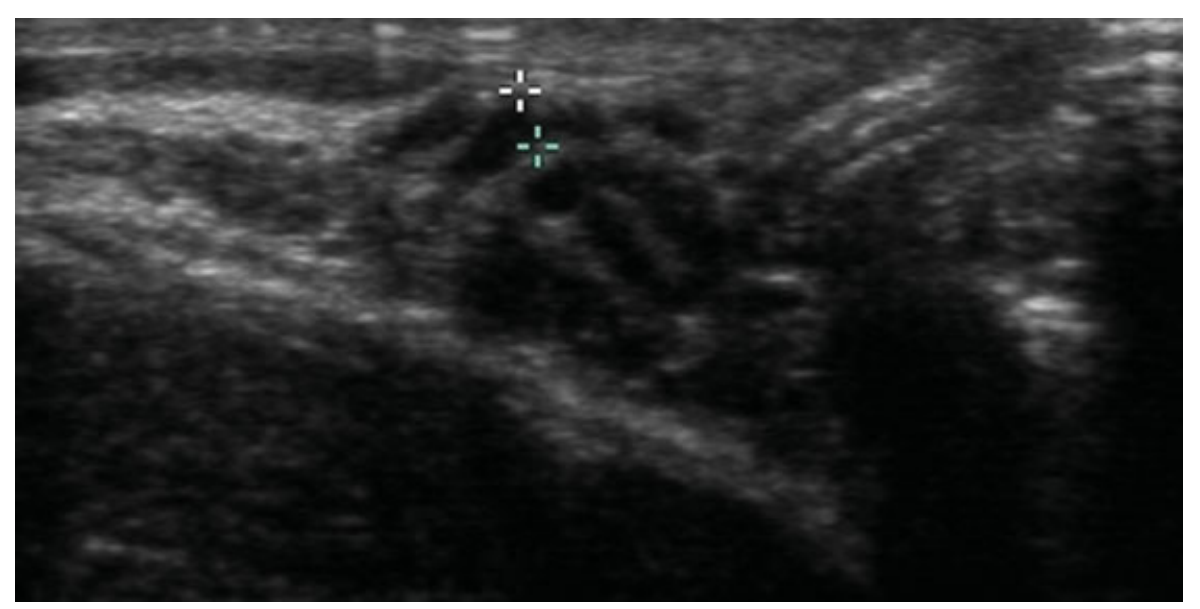

Fig. 1 Gray-scale ultrasound in a 14-year-old boy being evaluated for a left varicocele. There are multiple serpiginous anechoic vessels associated with the left scrotum, measuring up to $2.3 \mathrm{~mm}$ in diameter (calipers). 
a
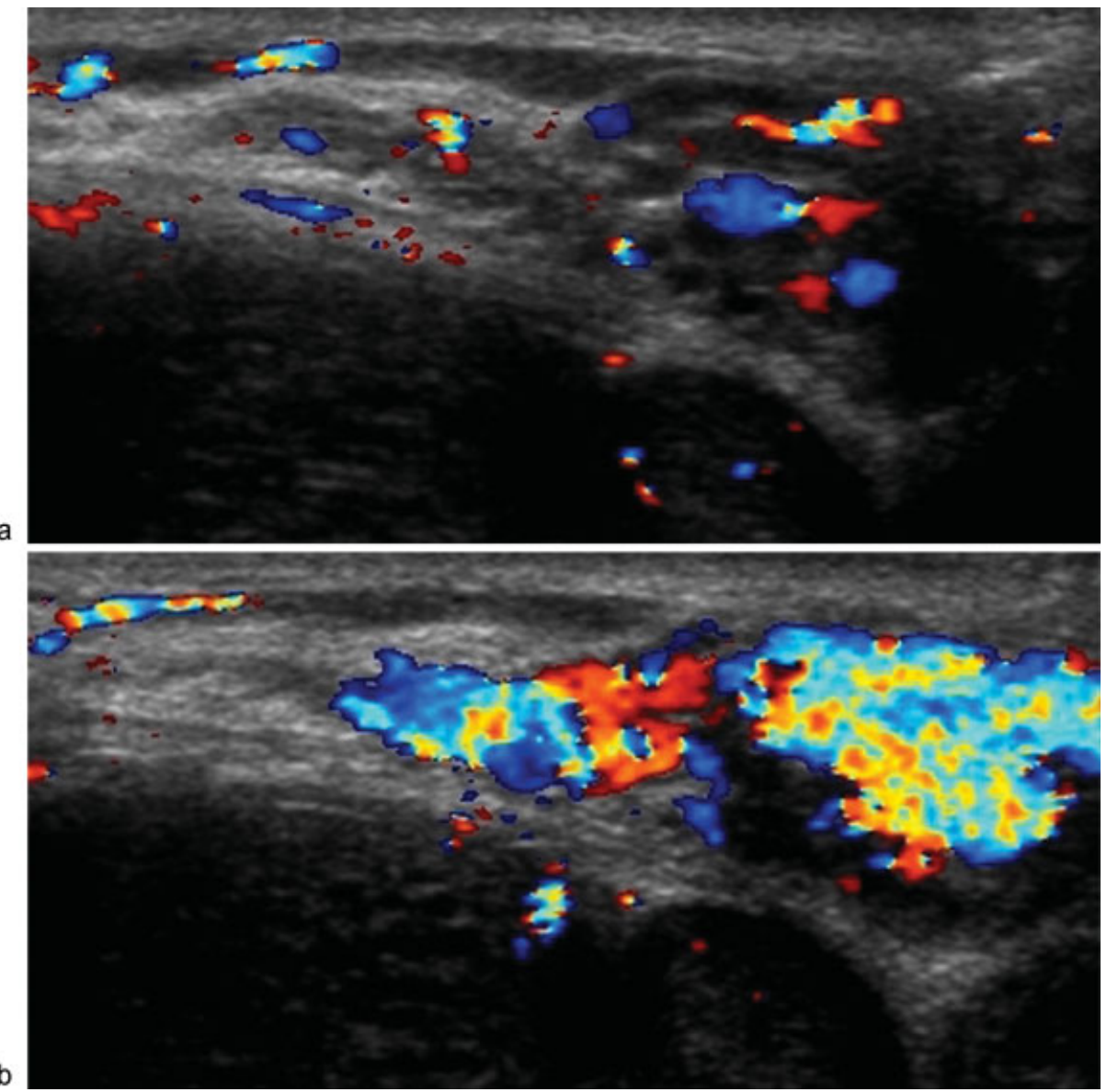

Fig. 2 Color Doppler ultrasound in a 14-year-old boy being evaluated for a left varicocele. Imaging was performed before (a) and during (b) Valsalva. During Valsalva, blood flow is increased.

documents the presence of reflux, checks for the presence of venous collaterals, and aids in planning for embolization ( - Fig. 4a, b). Some operators may opt to use a microcatheter at this point to gain access to the inferior internal spermatic vein.

Successful varicocele embolization has been described using a variety of embolic agents and sclerosants, with operator preference dictating embolic choice. Authors have reported using sclerosing agents, ${ }^{63,65}$ coils, ${ }^{58}$ liquid embolics, ${ }^{60,66}$ detachable balloons, ${ }^{58}$ and hot contrast. ${ }^{61}$ Earlier literature described the use of an "air-block" technique in which a small amount of air was injected prior to injecting the sclerosant. However, this has been shown to often be ineffective and is no longer used. ${ }^{67-69}$

Coil embolization is performed by advancing the catheter to the distal internal spermatic vein and embolizing the length of

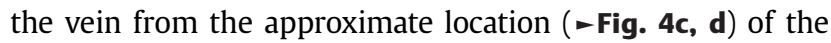
inguinal canal to its confluence with the left renal vein or inferior vena cava. If collaterals are large, they too are selectively embolized. Distal protection during embolization with sclerosant has been described several ways, including creating a nest of coils, using balloon occlusion, ${ }^{16}$ or with manual compression of the spermatic cord. ${ }^{63}$

Table 3 Ultrasound grading of varicoceles

\begin{tabular}{|l|l|}
\hline Grade 1 & $\begin{array}{l}\text { Reflux in the spermatic cord veins in the inguinal region while performing a Valsalva maneuver. } \\
\text { No appreciable scrotal varicocele }\end{array}$ \\
\hline Grade 2 & $\begin{array}{l}\text { Nondilated veins while supine. When standing dilated veins reach the upper pole of the testicle. } \\
\text { Reflux to upper pole veins only while performing a Valsalva maneuver }\end{array}$ \\
\hline Grade 3 & $\begin{array}{l}\text { Nondilated veins while supine. When standing dilated veins reach the lower pole of the testicle. } \\
\text { Reflux to lower pole veins only while performing a Valsalva maneuver }\end{array}$ \\
\hline Grade 4 & Dilated veins while supine with reflux while performing a Valsalva maneuver \\
\hline Grade 5 & Dilated veins that reflux without performing a Valsalva maneuver \\
\hline
\end{tabular}


a
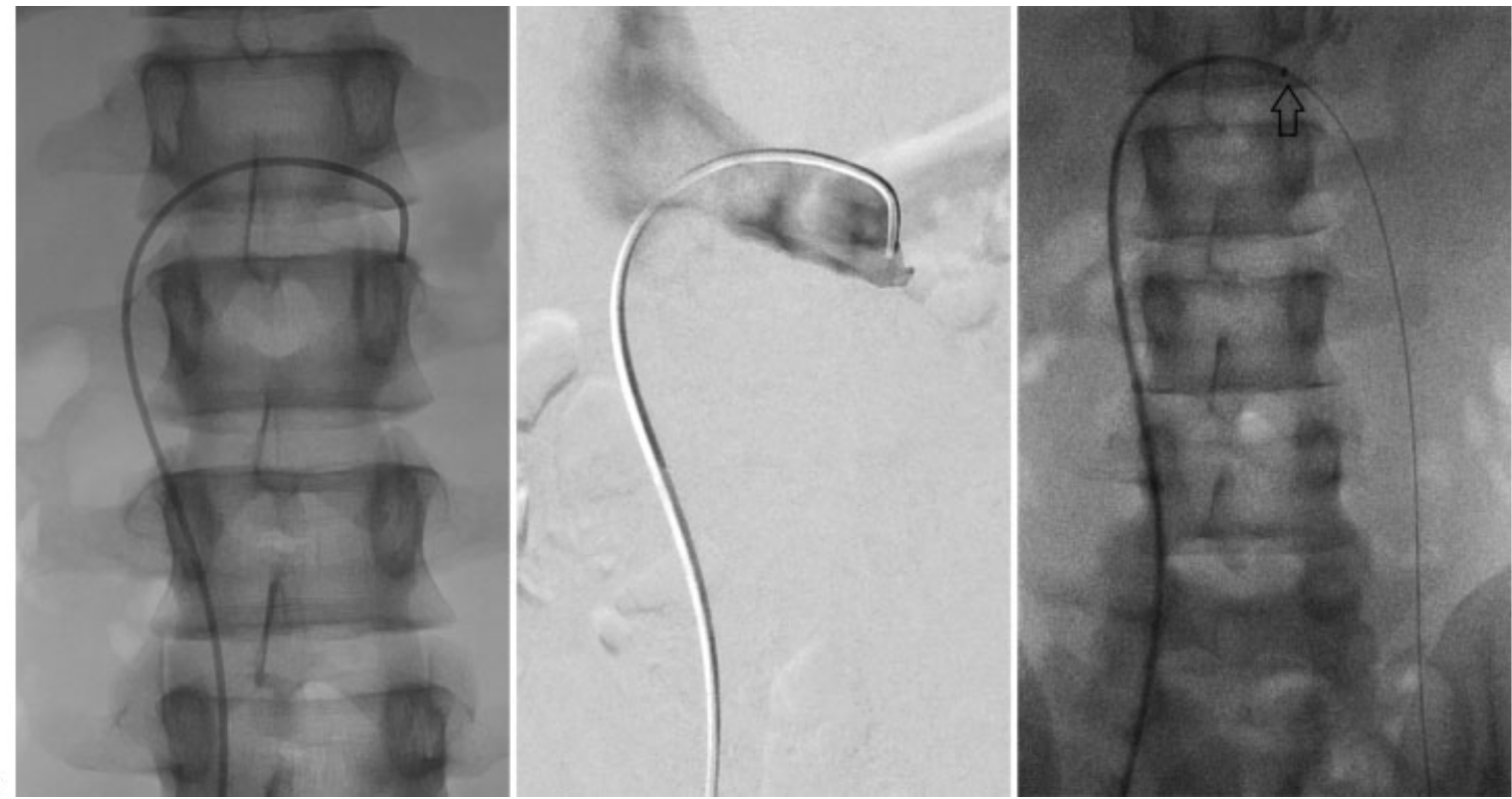

b, c

Fig. 3 A 17-year-old male undergoing left varicocele embolization with access via the right common femoral vein. (a) Selective catheterization of the left renal vein; (b) Left renal venogram; (c) A 6F sheath was advanced into the left renal vein (arrow) for additional support.

\section{Outcomes}

As the initial treatment for varicoceles, percutaneous embolization is technically successful in 90 to $97 \%$, with recurrence rates ranging from 2 to $24 \%$; both of these ranges are comparable to surgery. ${ }^{16,70-72}$ Additionally, when comparing improvement in seminal parameters and pregnancy rates following percutaneous embolization versus surgery, there was no reported statistical difference between the two interventions. ${ }^{70}$
Percutaneous varicocele embolization is an excellent treatment option for patients with persistent or recurrent varicocele following varicocelectomy. Because this is often secondary to a persistent draining vein not treated during surgery, retrograde venography allows for visualization of the culprit vein. A 2011 review of persistent/recurrent varicoceles treated with percutaneous embolization demonstrated complete resolution in $80 \%$ and partial resolution in an additional $16 \%$ of cases. ${ }^{71}$

a
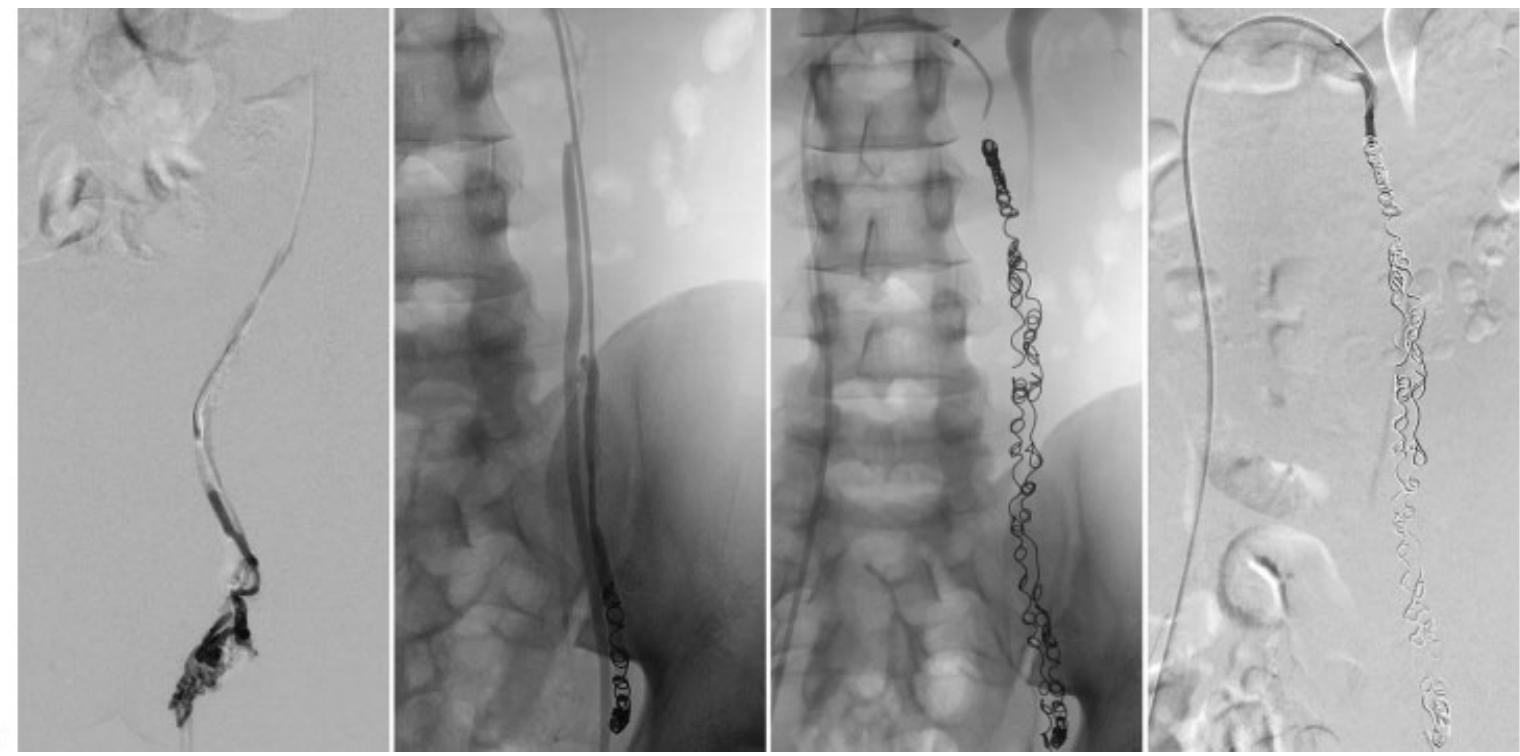

Fig. 4 A 17-year-old male requiring left varicocele embolization. (a) A $5 \mathrm{~F}$ catheter was positioned in the distal left internal spermatic vein and venogram was performed. Duplication of the distal internal spermatic vein is present; (b) venogram of the left internal spermatic vein after partial coil embolization, again showing partial duplication; (c, d) coil embolization with subsequent venogram demonstrating satisfactory occlusion. 
Treatment of varicoceles has been demonstrated to improve fertility. A Cochrane review of 10 studies including 894 participants demonstrated an increase in pregnancy rates following varicocele treatment compared with no treatment. ${ }^{73}$

\section{Complications}

The most common complaint following embolization is testicular pain that may last for up to 10 days. ${ }^{3,63}$ Such pain has been reported in up to $17 \%$ of patients. ${ }^{60,67,74}$ Other minor immediate complications include inguinal hematoma, ${ }^{67}$ temporary venotomy site pain, ${ }^{75}$ and contrast allergy. ${ }^{63}$ Multiple studies demonstrated no risk of hydrocele formation following embolization, likely due to sparing of the lymphatic system. ${ }^{29,62}$ However, a single study reported a hydrocele incidence of $4.5 \%$ of patients. ${ }^{48}$ It is uncertain if this was reactive to thrombophlebitis rather than being lymphatic in nature.

During venography, perforation of the internal spermatic vein and dissection of the IVC/renal vein may occur, reported in up to 4.6 and $4.1 \%$ of cases, respectively. This complication is usually without clinical consequence. ${ }^{67}$ Though rare, more serious complications from varicocele embolization have been described, including coil migration to the right atrium ${ }^{75}$ and pulmonary arteries, ${ }^{76}$ as well as bowel necrosis following sclerotherapy. $^{77}$

\section{Summary}

Percutaneous embolization is a safe and effective treatment option in the management of varicoceles, with comparable results to surgical varicocelectomy. Interventional treatment has the additional benefit of limiting surgical complications such as the development of a hydrocele, as well as being far less invasive. Additionally, the ability to visualize variant anatomy makes percutaneous embolization an important tool in the setting of failed surgical varicocelectomy.

\section{Disclosure}

None.

\section{References}

1 Nöske HD, Weidner W. Varicocele-a historical perspective. World J Urol 1999;17(3):151-157

2 Kaufman SL, Nagler HM. The varicocele: concepts of pathophysiology - present and future. World J Urol 1986;4(2):88-91

3 Halpern J, Mittal S, Pereira K, Bhatia S, Ramasamy R. Percutaneous embolization of varicocele: technique, indications, relative contraindications, and complications. Asian J Androl 2016;18(2):234-238

4 Rothman CM. The varicocele-1800. Urology 1980;15(1):99-100

5 Ivanissevich C, Gregorini H. Una nueva operacion para curar el varicocele. Sem Med 1918;25:575

6 Palomo A. Radical cure of varicocele by a new technique; preliminary report. J Urol 1949;61(3):604-607

7 Kaye KW. Modified high varicocelectomy: outpatient microsurgical procedure. Urology 1988;32(1):13-16

8 Tulloch WS. Varicocele in subfertility; results of treatment. BMJ 1955;2(4935):356-358
9 Hagood PG, Mehan DJ, Worischeck JH, Andrus CH, Parra RO. Laparoscopic varicocelectomy: preliminary report of a new technique. J Urol 1992;147(1):73-76

10 Little AF, Lavoipierre AM. Unusual clinical manifestations of the Nutcracker Syndrome. Australas Radiol 2002;46(2):197-200

11 Pallwein L, Pinggera G, Schuster AH, et al. The influence of left renal vein entrapment on outcome after surgical varicocele repair: a color Doppler sonographic demonstration. J Ultrasound Med 2004;23(5):595-601

12 Masson P, Brannigan RE. The varicocele. Urol Clin North Am 2014; 41(1):129-144

13 Zini A, Boman JM. Varicocele. In: Goldstein M, Schlegel PN, eds. Surgical and Medical Management of Male Infertility. Cambridge: Cambridge University Press; 2003:137-149

14 Mehta AL, Dogra VS. Intratesticular varicocele. J Clin Ultrasound 1998;26(1):49-51

15 Sofikitis N, Dritsas K, Miyagawa I, Koutselinis A. Anatomical characteristics of the left testicular venous system in man. Arch Androl 1993;30(2):79-85

16 Grieme B, Akman A, Albayati A, Timmreck EJ, Tanski EM, Venbrux AC. Management of male varicocele. In: Mauro MA, Murphy KPJ, Thomson KR, Venbrux AC, Morgan RA, eds. Image-Guided Interventions. 2nd ed. Philadelphia, PA: Saunders; 2014:559-562

17 Asala S, Chaudhary SC, Masumbuko-Kahamba N, Bidmos M. Anatomical variations in the human testicular blood vessels. Ann Anat 2001;183(6):545-549

18 Biswass S, Chattopadhyay JC, Panicker H, Anbalagan J, Ghosh SK. Variations in renal and testicular veins-a case report. J Anat Soc India 2006;55(2):69-71

19 Rosalino UAC, Latorre GC, Pinto AC, Toscano MP. Uncommon drainage of the gonadal vein: case report. Braz J Morphol Sci 2011;28(2):135-136

20 Fretz PC, Sandlow JI. Varicocele: current concepts in pathophysiology, diagnosis, and treatment. Urol Clin North Am 2002;29(4): 921-937

21 Clarke BG. Incidence of varicocele in normal men and among men of different ages. JAMA 1966;198(10):1121-1122

22 Practice Committee of American Society for Reproductive Medicine. Report on varicocele and infertility. Fertil Steril 2008;90 (5, Suppl):S247-S249

23 Levinger U, Gornish M, Gat Y, Bachar GN. Is varicocele prevalence increasing with age? Andrologia 2007;39(3):77-80

24 Canales BK, Zapzalka DM, Ercole CJ, et al. Prevalence and effect of varicoceles in an elderly population. Urology 2005;66(3):627-631

25 Diamond DA. Adolescent varicocele: emerging understanding. BJU Int 2003;92(Suppl 1):48-51

26 Raman JD, Walmsley K, Goldstein M. Inheritance of varicoceles. Urology 2005;65(6):1186-1189

27 Geatti O, Gasparini D, Shapiro B. A comparison of scintigraphy, thermography, ultrasound and phlebography in grading of clinical varicocele. J Nucl Med 1991;32(11):2092-2097

28 Ficarra V, Cerruto MA, Liguori G, et al. Treatment of varicocele in subfertile men: The Cochrane Review-a contrary opinion. Eur Urol 2006;49(2):258-263

29 Iaccarino V, Venetucci P. Interventional radiology of male varicocele: current status. Cardiovasc Intervent Radiol 2012;35(6):1263-1280

30 Jarow JP. Effects of varicocele on male fertility. Hum Reprod Update 2001;7(1):59-64

31 McClure RD, Khoo D, Jarvi K, Hricak H. Subclinical varicocele: the effectiveness of varicocelectomy. J Urol 1991;145(4):789-791

32 Evers JLH, Collins JA. Assessment of efficacy of varicocele repair for male subfertility: a systematic review. Lancet 2003;361(9372): 1849-1852

33 Comhaire FH, Kunnen M. Factors affecting the probability of conception after treatment of subfertile men with varicocele by transcatheter embolization with Bucrylate. Fertil Steril 1985; 43(5):781-786 
34 Dhabuwala CB, Hamid S, Moghissi KS. Clinical versus subclinical varicocele: improvement in fertility after varicocelectomy. Fertil Steril 1992;57(4):854-857

35 Cantoro U, Polito M, Muzzonigro G. Reassessing the role of subclinical varicocele in infertile men with impaired semen quality: a prospective study. Urology 2015;85(4):826-830

36 Seo JT, Kim KT, Moon MH, Kim WT. The significance of microsurgical varicocelectomy in the treatment of subclinical varicocele. Fertil Steril 2010;93(6):1907-1910

37 Sofikitis N, Miyagawa I. Effects of surgical repair of experimental left varicocele on testicular temperature, spermatogenesis, sperm maturation, endocrine function, and fertility in rabbits. Arch Androl 1992;29(2):163-175

38 Zorgniotti AW, Macleod J. Studies in temperature, human semen quality, and varicocele. Fertil Steril 1973;24(11):854-863

39 Goldstein M, Eid JF. Elevation of intratesticular and scrotal skin surface temperature in men with varicocele. J Urol 1989;142(3):743-745

40 Comhaire F, Vermeulen A. Varicocele sterility: cortisol and catecholamines. Fertil Steril 1974;25(1):88-95

41 Ito H, Fuse H, Minagawa H, Kawamura K, Murakami M, Shimazaki J. Internal spermatic vein prostaglandins in varicocele patients. Fertil Steril 1982;37(2):218-222

42 Hendin BN, Kolettis PN, Sharma RK, Thomas AJ Jr, Agarwal A Varicocele is associated with elevated spermatozoal reactive oxygen species production and diminished seminal plasma antioxidant capacity. J Urol 1999;161(6):1831-1834

43 Kilinç F, Kayaselcuk F, Aygun C, Guvel S, Egilmez T, Ozkardes H. Experimental varicocele induces hypoxia inducible factor-1alpha, vascular endothelial growth factor expression and angiogenesis in the rat testis. J Urol 2004;172(3):1188-1191

44 Lipshultz LI, Corriere JN Jr. Progressive testicular atrophy in the varicocele patient. J Urol 1977;117(2):175-176

45 Scott LS. Varicocele: a treatable cause of subfertility. BMJ 1961; 1(5228):788-790

46 Saleh R, Mahfouz RZ, Agarwal A, Farouk H. Histopathologic patterns of testicular biopsies in infertile azoospermic men with varicocele. Fertil Steril 2010;94(6):2482-2485, 2485.e1-2485.e2

47 Chawla A, Kulkarni G, Kamal K, Zini A. Microsurgical varicocelectomy for recurrent or persistent varicoceles associated with orchalgia. Urology 2005;66(5):1072-1074

48 Puche-Sanz I, Flores-Martín JF, Vázquez-Alonso F, Pardo-Moreno PL, Cózar-Olmo JM. Primary treatment of painful varicocoele through percutaneous retrograde embolization with fibred coils. Andrology 2014;2(5):716-720

49 Peterson AC, Lance RS, Ruiz HE. Outcomes of varicocele ligation done for pain. J Urol 1998;159(5):1565-1567

50 Kass EJ, Marcol B. Results of varicocele surgery in adolescents: a comparison of techniques. J Urol 1992;148(2 Pt 2):694-696

51 Muthuveloe DW, During V, Ashdown D, Rukin NJ, Jones RG, Patel P. The effectiveness of varicocele embolisation for the treatment of varicocele related orchalgia. Springerplus 2015;4:392

52 Dubin L, Amelar RD. The varicocele and infertility. In: Dubin L, Amelar RD, eds. Male infertility. Philadelphia, PA: Saunders; 1977:57-68

53 Dogra VS, Gottlieb RH, Oka M, Rubens DJ. Sonography of the scrotum. Radiology 2003;227(1):18-36

54 Sakamoto H, Saito K, Shichizyo T, Ishikawa K, Igarashi A, Yoshida H. Color Doppler ultrasonography as a routine clinical examination in male infertility. Int J Urol 2006;13(8):1073-1078

55 Liguori G, Trombetta C, Garaffa G, et al. Color Doppler ultrasound investigation of varicocele. World J Urol 2004;22(5):378-381

56 Ghanem H, Anis T, El-Nashar A, Shamloul R. Subinguinal microvaricocelectomy versus retroperitoneal varicocelectomy: comparative study of complications and surgical outcome. Urology 2004; 64(5):1005-1009

57 Diegidio P, Jhaveri JK, Ghannam S, Pinkhasov R, Shabsigh R, Fisch H. Review of current varicocelectomy techniques and their outcomes. BJU Int 2011;108(7):1157-1172
58 Reyes BL, Trerotola SO, Venbrux AC, et al. Percutaneous embolotherapy of adolescent varicocele: results and long-term follow-up. J Vasc Interv Radiol 1994;5(1):131-134

59 Prasivoravong J, Marcelli F, Lemaître L, et al. Beneficial effects of varicocele embolization on semen parameters. Basic Clin Androl 2014;24(9):9

60 Urbano J, Cabrera M, Alonso-Burgos A. Sclerosis and varicocele embolization with N-butyl cyanoacrylate: experience in 41 patients. Acta Radiol 2014;55(2):179-185

61 Hawkins CM, Racadio JM, McKinney DN, Racadio JM, Vu DN. Varicocele retrograde embolization with boiling contrast medium and gelatin sponges in adolescent subjects: a clinically effective therapeutic alternative. J Vasc Interv Radiol 2012;23(2):206-210

62 Storm DW, Hogan MJ, Jayanthi VR. Initial experience with percutaneous selective embolization: a truly minimally invasive treatment of the adolescent varicocele with no risk of hydrocele development. J Pediatr Urol 2010;6(6):567-571

63 Gandini R, Konda D, Reale CA, et al. Male varicocele: transcatheter foam sclerotherapy with sodium tetradecyl sulfate-outcome in 244 patients. Radiology 2008;246(2):612-618

64 Sze DY, Kao JS, Frisoli JK, McCallum SW, Kennedy WA II, Razavi MK. Persistent and recurrent postsurgical varicoceles: venographic anatomy and treatment with N-butyl cyanoacrylate embolization. J Vasc Interv Radiol 2008;19(4):539-545

65 Di Bisceglie C, Fornengo R, Grosso M, et al. Follow-up of varicocele treated with percutaneous retrograde sclerotherapy: technical, clinical and seminal aspects. J Endocrinol Invest 2003;26(11):1059-1064

66 Vanlangenhove P, Everaert K, Van Maele G, Defreyne L. Tolerance of glue embolization under local anesthesia in varicoceles: a comparative study of two different cyanoacrylates. Eur J Radiol 2014; 83(3):559-563

67 Seyferth W, Jecht E, Zeitler E. Percutaneous sclerotherapy of varicocele. Radiology 1981;139(2):335-340

68 Sigmund G, Bähren W, Gall H, Lenz M, Thon W. Idiopathic varicoceles: feasibility of percutaneous sclerotherapy. Radiology 1987;164(1):161-168

69 Lenz M, Hof N, Kersting-Sommerhoff B, Bautz W. Anatomic variants of the spermatic vein: importance for percutaneous sclerotherapy of idiopathic varicocele. Radiology 1996;198(2): 425-431

70 Shlansky-Goldberg RD, VanArsdalen KN, Rutter CM, et al. Percutaneous varicocele embolization versus surgical ligation for the treatment of infertility: changes in seminal parameters and pregnancy outcomes. J Vasc Interv Radiol 1997;8(5):759-767

$71 \mathrm{Kim}$ J, Shin JH, Yoon HK, et al. Persistent or recurrent varicocoele after failed varicocoelectomy: outcome in patients treated using percutaneous transcatheter embolization. Clin Radiol 2012;67(4): 359-365

72 Beddy P, Geoghegan T, Browne RF, Torreggiani WC. Testicular varicoceles. Clin Radiol 2005;60(12):1248-1255

73 Kroese ACJ, de Lange NM, Collins J, Evers JLH. Surgery or embolization for varicoceles in subfertile men. Cochrane Database Syst Rev 2012;10(10):CD000479

74 Gazzera C, Rampado O, Savio L, Di Bisceglie C, Manieri C, Gandini G. Radiological treatment of male varicocele: technical, clinical, seminal and dosimetric aspects. Radiol Med (Torino) 2006; 111(3):449-458

75 Sivanathan C, Abernethy LJ. Retrograde embolisation of varicocele in the paediatric age group: a review of 10 years' practice. Ann R Coll Surg Engl 2003;85(1):50-51

76 Chomyn JJ, Craven WM, Groves BM, Durham JD. Percutaneous removal of a Gianturco coil from the pulmonary artery with use of flexible intravascular forceps. J Vasc Interv Radiol 1991;2(1): 105-106

77 Vicini P, Di Pierro GB, Grande P, et al. Large bowel infarct following antegrade scrotal sclerotherapy for varicocele: a case report. Can Urol Assoc J 2014;8(9-10):E641-E643 